\title{
Application of IOT Technology and Remote Control Technology in
}

\author{
Industrial Automation Control
}

\author{
Xiangui SHI,Dekui Kong \\ AnHui XinHua University,School of Information Science and Technology, HeFei 230088
}

Keywords: Remote control technology, IOT technology, Industrial automation control, Application.

\begin{abstract}
Along with the continuous progress of science and technology, industrial automation has been more and more widely applied in various industries. As it raises labor productivity and breaks the confinement to human labor, it has played a significant role in China's economic construction. This paper mainly discussed the influence exerted by the application of remote control and internet of things (IOT in abbreviation) technology in industrial automation control on the development of industrial automation system.
\end{abstract}

\section{Introduction}

Industrial automation technology has been widely promoted and applied in China, whose effectiveness has been fully embodied in industrial automated production practice. With the progress of era and the development of information technology, industrial automation technology is in constant reform. Remote control and IOT technology as an important part of industrial automation, play an extremely important role in the actual industrial production and application, which have created great economic and social benefits for industrial automation companies.

\section{Application of Remote Control in Industrial Automation Control}

Principles of Remote Control. Remote control should follow the following principles. Firstly, it should meet the needs of different levels of personnel. Enterprise's production management is in need of close cooperation between decision-making, management and operation personnel. So remote control applied in the industrial automation system will have to satisfy the comprehensive requirement of management personnel, the far view ones of decision-making personnel and the specific operating ones of operating personnel Secondly, safety should be put in the first place. Safety is most concerned in the production of various industries as security problems in the process of industrial automated production determine enterprises' survival and development. Therefore, in the process of implementing remote control in industrial automation, collection of real-time production data should meet the requirement of both index and the safety of the production control system at the same time. Thirdly, production monitoring videos should be aligned with real-time production scenes. Only the consistence between the field situation of manufacturing and monitoring videos can ensure the effectiveness of remote control. Managerial staff can implement real-time control and supervision over the manufacturing process and master the field situation of the manufacturing site through the monitoring pictures of and supervision. This requires consistence between the pictures of manufacturing and of office monitoring in adopting remote control in industrial automation applications to make. Fourthly, real practicality should be achieved. The practicability of industrial automation remote control lies in real-time display, testing, storing of measured data, metering, statements printing, etc. That is, remote control has to realize its value and bring enterprises beneficial production results in its application in the manufacturing process of industrial automation. 
Practical Application. Firstly, remote control is the centralized control over the production equipment of in the process of industrial production. In industrial automation systems, the most distinguishing feature of remote control is centralized control of the production equipment in the process of production. Through the real-time monitoring over automation equipment, the staff can timely discover and solve the failures appeared in the process of production and through analysis displayed on the computer they can make judgement of the working condition of automation equipment in the production field; thus effectively ensuring normal operation of industrial automation in the production process. Fig. 1 is the remote application of schematic diagram of fault diagnosis system. Secondly, remote control realizes adjustment and control over industrial automation system. Remote control can effectively realize the integration of automation systems in industrial automation, and through computer network for overall operation management, really brings about unmanned supervision over the production process. Moreover, the feedback information of remote control, clearer and closer to the actual production field, can help to improve the accuracy of data analysis made by staff, thus effectively guaranteeing the safety of the industrial automation system. Thirdly, remote control monitors over the industrial manufacturing process. As the production process of industrial automation is very complicated, there are great difficulties in actual control. Even a little bit of careless operation will cause great damage. Therefore, in order to ensure the normal operation of each production process, real-time monitoring must be implemented for each production process through the integration of management. Remote control can effectively realize the integration of control and management over industrial automated production process as well as monitor every component in the production process, thus ensuring the normal operation of industrial automation.

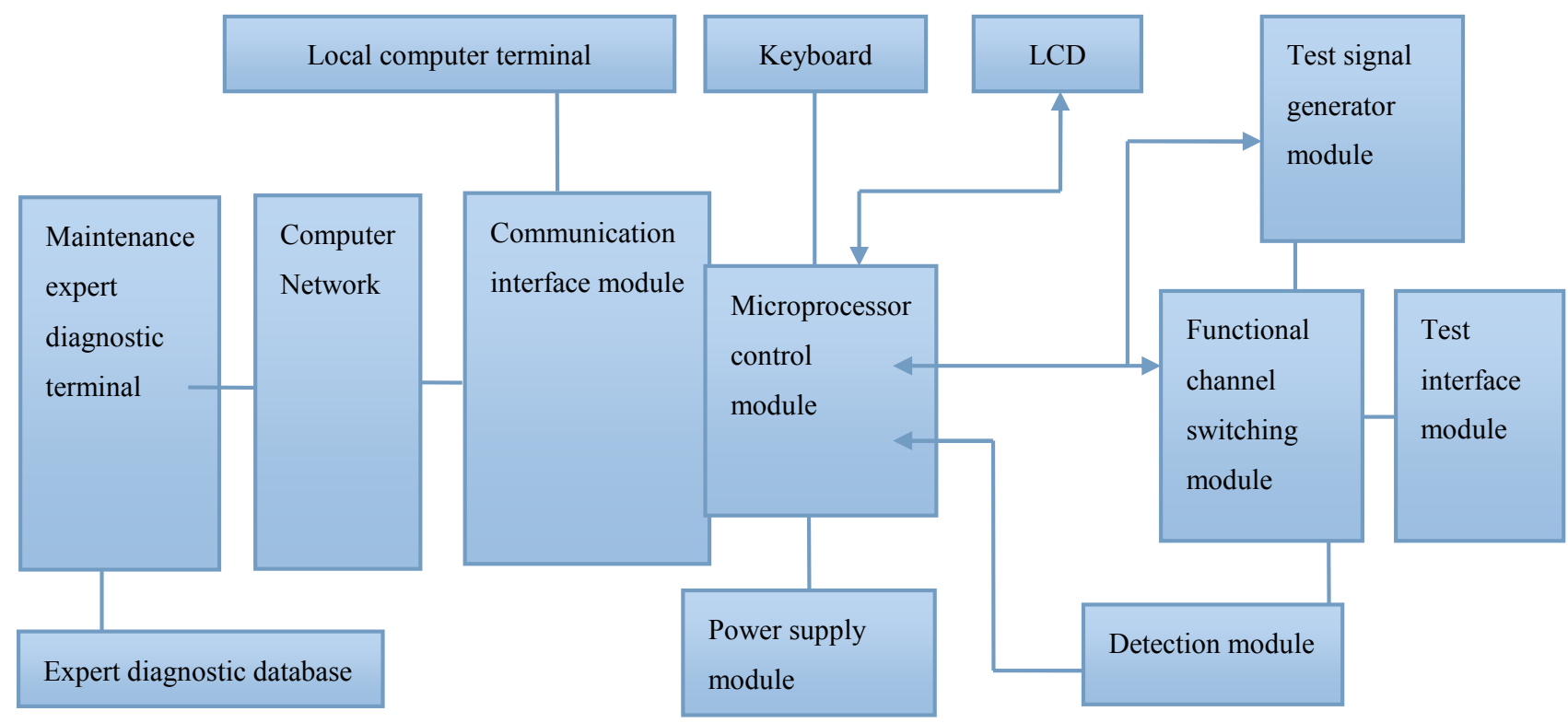

Figure 1 Schematic Diagram of Remote Application of Fault Diagnosis System

Application Benefit. Firstly, remote control creates benefits in the industrial automated production. It can improve production efficiency, timely eliminate faults in the manufacturing process reduce costs and promote the enterprise's survival and development with its application in industrial automated production. Its benefit in industrial automated production process is mainly reflected in two aspects. Secondly, remote control generates economic benefits in industrial automated production. Application of remote control technology in industrial automated production can effectively strengthen the functions of automation system, improve production efficiency in the industrial production process and reduce the cost of investment, thus beneficial to improve the management level and economic benefits of the enterprise. Thirdly, remote control social brings social benefits in the industrial automated production. With the progress of the times and the development of information, the core requirement of the development trend of modern industrial is 
informatization and automation. Remote control system has improved production safety in the process of production for the enterprise and actively promoted the enterprise's safety production and commanding and dispatching. Meanwhile, it promotes management informatization of the enterprise, making originally complex automation control program into the integration of simple control systems having certain significance for the production and development of the enterprise. It can be said that remote control creates a lot of social benefits for industrial automated production.

\section{Application of the IOT Technology in Industrial Automated Control}

Key Technology. (a) Identification technology. In the exchange process of stuff on the IOT, each thing has a specific and unique identification code, which is likely to be either permanently or temporarily set. However, due to the relatively complex structure of the IOT, it is necessary to install the device on the original object that can identify its internal constituents. (b) Architecture technology. Architecture technology is based on the demand for identification technology. Architecture technology of the IOT is to establish and maintain a relationship of mutual operability between suppliers and demanders in heterogeneous information system that can be achieved through many ways in IOT technology, among which the most direct is to establish a shared mode between suppliers and demanders so as to realize the sharing of resources, information and data. But the premise of the sharing is that the operation space for the providers and demanders has certain limitation in the no language environment. This needs the support from the architecture IOT technology to ensure scalability, extensibility and modularity of the operating environment in the exchange process of the things. (c) Data and information processing technology. The application range of industrial automation is very wide, which involves whether in the process of production or in sales. In these process data and information processing IOT technology need to be adopted to collect industrial information and data and to provide analysis, output and differentiation of it. Semantic operability should be followed in the application of data and information processing technology of internet of things. In the process of using this kind of data and information, standard techniques should be employed to deal with them. Fig. 2 shows the four layer model of the internet of things.

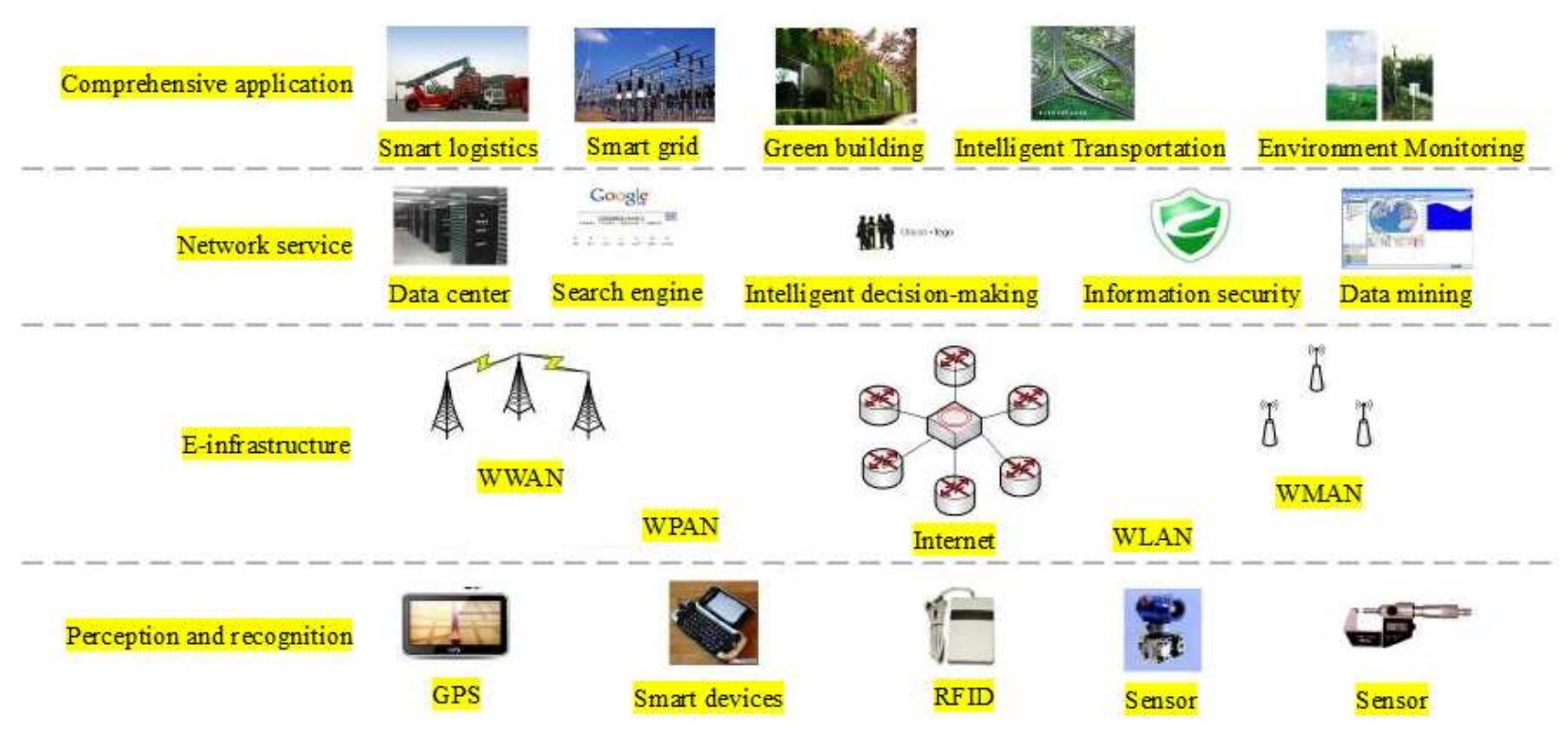

Figure 2 Four Layer Model of IOT

Practical Application. (a) Safety in production. IOT technology is both the core in industrial automation control system and the main norm in the industrial field as well as an important technology to ensure safety in production in various fields. In industrial automated production, IOT technology is employed to monitor the workers, environment and machinery, to detect and diagnose 
potential safety hazard and to track the position of the personnel. It helps managers to master in time and eliminate potential safety hazard, thus reducing economic losses and enhancing personal safety. (b) Manufacturing and production. At present, IOT technology has been widely used in various areas of industries, especially in the field of industrial production and manufacturing. It is one of the most important technologies, whose figure appears in every component in industrial production. For example, its installation on manufacturing equipment enables data collection by means of data and information processing technology and permits control over the consumption of raw materials and product quality in the process of production via its identification technology. IOT technology used industrial automated production and manufacturing can complete automated management of mechanical and industrial production. On improving production efficiency and production capacity, it can save more money for the enterprise. (C) Product informatization. In order to meet the needs of consumers and market, enterprises pay more and more attention to product informatization. IOT technology can achieve both remote control and real-time monitoring, so it is widely used in the field of product informatization. It can improve production and management intellectualization if used in product informatization. In the meantime of realizing industrial production information management, it can well realize product informatization. (d) Environmental protection. Industrial automation is available in environmental protection with the establishment of automatic monitoring system of environmental pollution, thus realizing online monitoring and control so as to protect the environment.

\section{Summary}

The comprehensive application of remote control and IOT technology can create a lot of benefits for both the enterprises and the society as well as prompt China's industrial production to go on the socialist road of sustainable development with Chinese characteristics, thus effectively guaranteeing the survival and development of industrial enterprises.

\section{References}

[1] Y. N. Luo, Internet of things technology and remote control of the smart home system design, Technology Innovation and Application. 3 (2013) 60-61.

[2] F. J. Wu, Research on the application of virtual reality technology based on Internet of things in the field of remote control, Discovering Value. 2 (2014) 44-45.

[3] J. R. Li. IOT application in household security and its key technology. Popular Science \& Technology. 6 (2012) 69-70.

\section{Author in brief}

Xiangui SHI, born in Hefei city of Anhui province in 1975, of Han nationality, master, lecturer, whose research direction is Computer application technolog, Automation technology.

Dekui Kong, born in shucheng city of Anhui province in 1966, of Han nationality, Undergraduate, His research is automation technology 